\title{
METODOLOGIAS PARTICIPATIVAS EM ESCOLAS DE CAMPINAS (SP) E ÁREAS DE ENTORNO: UMA ABORDAGEM TEÓRICO-METODOLÓGICA SOBRE O MEIO AMBIENTE
}

\author{
Participatory Methodologies in schools of Campinas (SP) and areas of environment: a \\ theoretical-methodological approach on the environment
}

Viviane Gomes de Araújo* Jeovanes Lisboa da Silva Filho **

Salvador Carpi Junior ***

\begin{abstract}
*Mestranda em Geografia, UNICAMP - vi.unicamp2010@gmail.com.
** Mestrando em Geografia, UFPB - jeovanelisboa@hotmail.com.

*** Geógrafo, Profissional de Apoio à Pesquisa e Ensino, Laboratório de Geomorfologia e Análise Ambiental, IGE - UNICAMP . salvador@ige.unicamp.br.
\end{abstract}

Recebido em 18/08/2018. Aceito para publicação em 26/08/2018.

Versão online publicada em 03/09/2018 (http://seer.ufrgs.br/paraonde)

\section{Resumo:}

A luz de assuntos como degradação e conservação do meio ambiente, metodologias participativas, formação de professores e educação ambiental, este trabalho apresenta uma experiência de ensino e pesquisa realizada durante o curso de capacitação de professores intitulado "Metodologias Participativas em escolas de Campinas (SP) e áreas de entorno", ministrado no segundo semestre de 2016 para professores da rede estadual de ensino do Estado de São Paulo, da cidade de Campinas e que teve como objetivo principal abordar metodologias participativas voltadas para a identificação de riscos ambientais e compreensão socioambiental do entorno de algumas escolas estaduais campineiras, através da participação e percepção de seus próprios professores e alunos.

Palavras-chave: Metodologias participativas; formação de professores; meio ambiente.

\begin{abstract}
:
In the light of subjects like environmental degradation and conservation, participatory methodologies, professional training of teachers and environmental education, this study presents an experiment about education and research conducted during the teachers training course entitled "Participatory Methodologies in Campinas (SP) and Surrounding Area's Schools", held in the second half of 2016 for teachers of the São Paulo state system. The course's main goal was to approach participatory methodologies aimed to the identification of environmental risks in the surrounding areas of some schools, which was accomplished by the participation of their own teachers and students.
\end{abstract}

Key-words: Participatory Methodologies; Teachers Training; Environment.

\section{Introdução}

De frente com as atuais relações sociais, políticas e econômicas da atualidade que tem como pano de fundo o sistema econômico capitalista, a preservação e conservação do meio ambiente, assim como alternativas sustentáveis, costumam ser pouco priorizadas pela sociedade.

A degradação do meio ambiente é um problema grave e diz respeito à qualidade de vida de todas as aglomerações humanas. Tal preocupação deve fazer parte da vida de cada cidadão, pois é responsabilidade de todos contribuir e participar do processo de conscientização ambiental, para que assim, atitudes que minimizem ou cessem os problemas ambientais sejam tomadas com mais 
frequência.

Neste sentido, o papel da escola se faz fundamental como forma de inserir aos estudantes noções básicas da importância da preservação e conservação da natureza. Para isso, a Educação Ambiental (EA) pode ser um caminho a ser seguido, pois oferece a possibilidade de se trabalhar com a "participação individual e coletiva, permanente e responsável, na preservação do equilíbrio do meio ambiente, entendendo-se a defesa da qualidade ambiental como um valor inseparável do exercício da cidadania." (PNEA, Lei 9.795/99).

Para alguns autores, por conta das discussões sobre a importância de se preservar e conservar o meio ambiente serem pautadas na relação homem x natureza, o termo educação socioambiental vem sendo mais utilizado ao invés de apenas educação ambiental. Segundo Silva (2011) pode-se dividir educação socioambiental em dois princípios: o da educação como possibilidade de liberdade e consciência (FREIRE, 1979) e do debate crítico do modelo de desenvolvimento e de industrialização que se afirmou ao longo do século XX (PORTO-GONÇALVES, 2006). Estes princípios abrem um leque ainda maior para o professor poder desenvolver diversos assuntos, de diversas maneiras, sobre a temática ambiental junto aos seus alunos em sala de aula.

Dentro deste contexto, a Geografia, por ser tratar de uma ciência que possui ampla abertura para a aproximação de discussões sobre as problemáticas ambientais, é facilitadora do trabalho do professor quando este precisa apresentar aos alunos assuntos sobre a questão ambiental e sua relação com a sociedade. Sendo assim, conforme Cavalcanti (1998), a Geografia é, portanto, uma disciplina escolar que visa desenvolver a criticidade dos estudantes acerca de aspectos e fenômenos que os rodeiam e fazem parte do espaço geográfico cotidiano vivenciado por eles, assim como das consequências geradas por estes aspectos e fenômenos ao meio físico e social.

Neste sentido, a Educação Ambiental, e/ou a Educação Socioambiental, se demonstram como fortes aliadas da Geografia para o estabelecimento de um diálogo apropriado à realidade dos alunos, conduzindo-os à cidadania. (BOTÊLHO e SANTOS, 2015).

No cenário educacional a tarefa do professor em ensinar sempre foi desafiadora, e para que o mesmo obtenha sucesso nessa empreitada, é necessário ter uma formação consistente, baseada em bons cursos de licenciatura, além de vasta experiência e vivência no ramo educacional. Nesse sentido, o apoio da Educação Ambiental (EA), os auxilia em seu processo de formação e lhes oferecem chances de realizar o exercício de:

\footnotetext{
Repensar práticas sociais e o papel dos professores como mediadores e transmissores de um conhecimento necessário para que os alunos adquiram uma base adequada de compreensão essencial do meio ambiente global e local, da interdependência dos problemas e soluções e da importância da responsabilidade de cada um para construir uma sociedade planetária mais equitativa e ambientalmente sustentável (TRISTÃO, 2004, pg. 18).
}

Desta forma, perante o papel fundamental que os profissionais da educação, mais especificamente os professores, possuem na arte de ensinar, somado a importância de trazer à tona discussões relacionadas a questão ambiental e suas possíveis formas de abordagem na escola, este trabalho apresenta os principais resultados e discussões de uma experiência didática realizada com alguns professores de Geografia, História, Química, Sociologia e Filosofia da Rede Estadual de Ensino do estado de São Paulo, atuantes na cidade de Campinas.

Tudo isso foi possibilitado através do oferecimento e aplicação do curso de capacitação de professores "Metodologias participativas em escolas de Campinas (SP) e áreas de entorno", o qual foi idealizado e ministrado pelo Prof. Dr. Salvador Carpi Junior do Instituto de Geociências da Universidade Estadual de Campinas (Unicamp), com o apoio da Diretoria Leste de Ensino da cidade de Campinas e de profissionais, professores e estudantes também do Instituto de Geociências da Unicamp.

Importante destacar que, como forma de realizar a identificação e posterior análise crítica dos 
principais problemas que afetam o meio ambiente das áreas mapeadas pelos professores e alunos das escolas participantes deste projeto, a percepção das pessoas que convivem diariamente com estes problemas foi explorada através da aplicação do Mapeamento Ambiental Participativo (MAP), metodologia participativa, que ajuda na identificação de riscos ambientais, vulnerabilidades sociais e ambientais, potencialidades do espaço, dentre outros.

\title{
2. Educação ambiental na escola: a importância de se discutir assuntos relacionados a degradação e conservação do meio ambiente
}

\begin{abstract}
A terra existiu sem nossos imagináveis antepassados, poderia muito bem existir hoje sem nós e existirá amanhã ou ainda mais tarde sem nenhum de nossos possíveis descendentes, mas nós não podemos existir sem ela. (SERRES,1990 apud SOUZA, 2014).
\end{abstract}

É certo que a Educação Ambiental (EA) é de extrema importância para a sociedade contemporânea, tendo em vista a voraz e avassaladora intervenção humana no meio ambiente como um todo, o que inclui a vegetação, solo, recursos hídricos e entre tantos outros elementos que fazem parte do sistema ambiental, sem esquecer-se dos animais.

Para tanto, verifica-se a importância da (EA) no setor mais formalizado de educação, procurandose despertar um olhar crítico dos discentes para as problemáticas socioambientais na expectativa de haver mudanças de percepção e valores de como agir, pensar e sentir no e com o meio ambiente ao seu entorno com ética e responsabilidade no proceder das ações.

Sendo assim, é importante atentar-se para o que destaca Santos; Leal, (2016) onde, ambos afirmam que o Brasil instituiu a Política Nacional de Educação Ambiental de acordo com a (Lei no 9.795/1999), evidenciando ainda mais sua importância no âmbito escolar. Desta forma, a partir desta Lei, o Ministério da Educação (MEC) instituiu a obrigatoriedade das instituições educacionais em incluir a Educação Ambiental em todos os níveis e modalidades de ensino.

Outro fator que cabe evidenciar é que a (EA) é, por natureza, interdisciplinar e transdisciplinar, uma vez que se trata de uma temática extremamente complexa e, ao mesmo tempo urgente de ser trabalhada no universo escolar. Neste contexto, trazemos à tona o educador-geógrafo francês Edgar Morin (2011) que realça o quão é essencial um pensamento complexo que faça interconexões no âmbito do ensino, e da Educação Ambiental em particular, tendo em vista a sua necessidade para a sustentabilidade sob seus variados aspectos, o econômico, social, ambiental, cultural, o que foge de uma prática mais tecnicista e tradicional de fazer educação.

Assim, os professores no âmbito escolar, devem estar atentos para as desenfreadas formas de degradação dos recursos in natura, e assim, serem capazes de criar ponderações em seus alunos, orientando-os de seus deveres enquanto um ser cidadão, e de sua responsabilidade de pensar o meio ambiente começando pelo seu lugar, pois, como enfatiza Amador (2016):

As questões que norteiam a contemporaneidade estão permeadas de preocupações ambientais que envolvem, mais do que nunca, o lugar e sua complexidade. Embora quase sempre perceba-se que o mesmo passe despercebido para a maioria das pessoas frente à frenética dinâmica que envolve os diversos âmbitos social, econômico, cultural e ecológico. (AMADOR, 2016, p. 20).

Embora essa autora provoque reflexões a respeito do lugar, os quais geralmente passam despercebidos diante das problemáticas ambientais, ao mesmo tempo realça que essas preocupações envolvem, diretamente o locus que estamos inseridos cotidianamente. Por isso a (EA) é de extrema importância, sobretudo quando aplicada levando em consideração a realidade que o aluno está 
inserido, pois a educação é o fio condutor que possibilita o empoderamento de conhecimento.

É patente que teremos obstáculos que irão criar dificuldades no caminho do ensino, e isso acontece e irá continuar a acontecer em todas as instâncias educativas, mas se faz necessário pensar conforme o que Loureiro (2007) coloca na seguinte reflexão:

O desafio é grande e não deve ser visto como desanimador ou angustiante. 0 prazer de ser educador ambiental reside não na certeza dos resultados, mas na construção permanente de novas possibilidades e reflexões que garantam o aprendizado, o respeito às múltiplas formas de vida e ao planeta a esperança de que podemos, sim, construir um mundo melhor para todos, igualitário, culturalmente diverso e ecologicamente viável. (LOUREIRO, 2007, p. 71).

\section{Metodologias participativas no contexto escolar: um enfoque para o Mapeamento Ambiental Participativo}

A escola enquanto espaço de busca pelo conhecimento no âmbito do processo de ensinoaprendizagem, deve estimular a troca de saberes por meio da participação numa perspectiva dialógica, onde todos os atores envolvidos devem externar seus anseios com base em suas percepções, atitudes e valores ao meio ambiente. Dessa forma, verifica-se a importância da implementação das metodologias de cunho participativo, onde se inclui o Mapeamento Ambiental Participativo (MAP), o qual pode contribuir positivamente para identificação de problemas e, também, potencialidades ambientais, uma vez que, conforme Dagnino; Carpi Junior (2016), ele é semelhante a um ato político onde as pessoas são chamadas a se reunir e são ouvidas, num processo que valoriza a cultura, a memória coletiva, a percepção, a linguagem popular e a experiência histórica dos participantes.

A primeira experiência de Mapeamento Ambiental Participativo (MAP) realizada em âmbito escolar ocorreu na Escola Estadual Francisco Pessoa, localizada no bairro Ana Jacinta, município de Presidente Prudente/SP (CARPI JUNIOR; LEAL; DIBIESO, 2012). Na ocasião, alunos da faixa etária aproximada entre 12 e 14 anos elaboraram cerca de v35 mapas, de utilizando do conhecimento do bairro e dos arredores da escola, inclusive com percurso para observações em campo.

Até então, os trabalhos de Mapeamento Ambiental Participativo, descritos por Dagnino; Carpi Jr (2016), foram realizados em inúmeros contextos de atividades acadêmicas, de extensão ou especialização, de apoio a gestão de bacias hidrográficas, entre outras, mas não relacionados diretamente às atividades escolares.

Outro trabalho pioneiro foi realizado em Campinas/SP, no qual Briguenti (2013), promoveu atividades com seus alunos por meio de trabalho de campo e posterior produção de mapas com ênfase em riscos ambientais em torno de escola localizada ás margens do Ribeirão das Anhumas. Os aspectos que tiveram destaque no trabalho de campo foram relacionados às temáticas: transito, violência e lixo, representadas por meio de sinais, anotações, fotos, entrevistas e filmagens que significaram barulho, medo, fluxo de automóveis, fluxo de pessoas, degradação, calor, chuva, lazer, mau cheiro etc. A proposta de ensino implementada proporcionou mapas denominados de perceptivos e participativos, que possibilitaram trabalhar conteúdos escolares, por meio de ações educativas que considerem a história e as relações do aluno com o local.

O MAP oportuniza encontrar e articular várias faces de um trabalho participativo, que vem sendo aplicado recentemente no contexto escolar para que, em algum ponto no futuro, possa contribuir na sustentabilidade dos recursos naturais. Sobretudo quando aplicado sob ponto de vista da Topofilia que é entendida como os laços afetivos da pessoa com o meio físico-material, ou seja, é o amor humano pelo lugar, é pensar nesse locus, o qual temos a nossa identidade e a sensibilidade de refletir, no entanto, agregando valores, os quais são de ordem subjetiva (TUAN, 2012).

Ao referir-se à participação social, a mesma nos remete a pensar que os envolvidos nesse processo externarão a sua percepção sobre assuntos variados de sua realidade, sejam eles saúde pública, 
poluição, enchentes, saneamento, riscos ambientais entre tantos outros. Essa percepção, por sua vez, está baseada nos valores pessoais, formação acadêmica, experiência de vida, formação familiar, religiosa e várias outras peculiaridades inerentes a cada contexto e visão de mundo, do locus que os cerca.

No contexto da participação onde é fomentada a troca de saberes, é importante que se busque respeito e ética por parte de todos os envolvidos. Logo, através do empoderamento de ideias, acreditase que se pode transformar a sociedade e o lugar para melhor, buscando o ponto de equilíbrio para a tomada de decisões.

Mas, para isso, é importante um trabalho que envolva a participação da comunidade. É nesse contexto que surge a escola favorecendo o apoderar-se de conhecimento pelos cidadãos conscientes e conhecedores dos problemas de ordem ambiental do lugar, e que esses trabalhem integradamente, mas não de maneira rígida como habitualmente está-se acostumado a fazer, e sim, com conhecimento, discernimento e respeito, mostrando possibilidades com o quesito ética norteando a condução dos trabalhos.

\section{Aplicação do minicurso "Metodologias Participativas nas escolas de Campinas (SP) e áreas de entorno"}

O minicurso "Metodologias participativas nas escolas de Campinas (SP) e áreas de entorno" foi aplicado no período matutino em alguns sábados dos meses de setembro, outubro e novembro de 2016, com aulas presenciais e não presenciais, realizadas em salas do prédio da Diretoria de Ensino Campinas Leste, com um total de 30 horas.

Nas atividades presenciais foram abordados aspectos teóricos, metodológicos, descrição de experiências, treinamentos práticos, debates, solicitação de um trabalho de conclusão de curso e por fim, a apresentação deste. No decorrer do minicurso participaram cerca de 15 professores que se distribuíam nas disciplinas Geografia, Sociologia, Biologia, Química e Filosofia.

Após a identificação de cada professor e das escolas onde ministravam aulas, foi possível realizar a elaboração de mapas base contendo a localização destas escolas, assim como seus principais pontos de referência e arruamentos presentes em suas áreas de entorno. Esse material foi feito com o propósito de ser utilizado no desenvolvimento da atividade prática de conclusão do minicurso, a qual foi proposta aos professores e realizada por eles em suas escolas, onde seus alunos puderam apontar os riscos socioambientais percebidos em suas áreas de estudo.

Nos dias das atividades não presenciais, foi orientado aos professores que trabalhassem em suas escolas a organização para o desenvolvimento da preparação de materiais, práticas participativas e realização de percursos no entorno das escolas.

Abaixo seguem os tópicos do plano de atividades do minicurso, elaborados e apresentados aos professores participantes pelo Prof. Dr. Salvador Carpi Junior:

a) Aula 1 (presencial): apresentação dos participantes e descrição geral do curso; conceitos e aspectos gerais sobre ambiente urbano, paisagem, lugar, percepção, educação ambiental, participação social, entre outros (03 horas);

b) Aula 2 (presencial): metodologias participativas e experiências realizadas; aspectos socioeconômicos e ambientais sobre Campinas e área de abrangência da Diretoria de Ensino Campinas Leste; esclarecimentos sobre as atividades não presenciais (03 horas);

c) Aula 3 (não presencial): pesquisa documental e bibliográfica sobre a escola e sua área de entorno, bairros vizinhos e distritos (03 horas);

d) Aula 4 (presencial): organização e preparação de material digital e impresso (mapas base); esclarecimentos sobre a metodologia de mapeamento participativo (03 horas); 
e) Aula 5 (não presencial): aplicação da primeira etapa do mapeamento Ambiental Participativo nas escolas, com a "alfabetização geográfica", definição dos elementos básicos nos mapas, escolha de legenda e início de inserção das informações (03 horas);

f) Aula 6 (presencial): apresentação preliminar do material produzido nas escolas, esclarecimentos sobre as dúvidas e questões técnicas, preparação do material para a segunda etapa do mapeamento ambiental participativo (03 horas);

g) Aula 7 (não presencial): aplicação da segunda etapa do Mapeamento Ambiental Participativo nas escolas, com a inserção dos insumos gráficos temáticos representando os aspectos positivos e negativos do ambiente, e registro de informações textuais (03 horas);

h) Aula 8: (não presencial): realização de trabalhos de campo nas áreas estudadas para checagem e complementação de informações (03 horas);

i) Aula 9: (não presencial); aplicação de questionários e entrevistas com moradores do bairro; registro e organização das informações e depoimentos (03 horas);

j) Aula 10 (presencial): apresentação dos resultados obtidos (mapas, gráficos, relatos, fotografias); debates, perspectivas de desdobramentos e encerramento (03 horas).

A aula 10, dia do encerramento do minicurso, aconteceu no dia 19 de novembro de 2016. Neste dia o encontro foi aberto ao público e teve como alvo docentes da rede estadual da Diretoria de Ensino Campinas Leste, além de colaboradores e convidados. Os objetivos deste encontro se pautaram em:

$\Rightarrow \quad$ Socializar a aplicação da metodologia de Mapeamento Ambiental Participativo (MAP), com adaptações necessárias ao contexto escolar, realizadas pelos participantes do curso.

$\Rightarrow \quad$ Socializar as vivências de observações frente a visitas in loco, realizadas pelos participantes do curso.

$\Rightarrow \quad$ Sensibilizar os professores para atuarem como mediadores junto aos seus alunos e a comunidade atendida pela escola, nas questões socioambientais.

$\Rightarrow \quad$ Contribuir para a formação de profissionais da educação pública, conscientes dos desafios e possibilidades na promoção de práticas pedagógicas socioambientais em suas múltiplas dimensões.

$\Rightarrow \quad$ Proporcionar momentos de estudo e de reflexão sob a luz do Currículo do Estado de São Paulo e das noções de competências e habilidades.

\section{Resultados e Considerações Finais}

Ao todo o minicurso contou com a participação de 15 professores, que se distribuíram em 11 escolas estaduais de Campinas onde foram desenvolvidas as atividades propostas e descritas acima. As escolas envolvidas foram: 1. CEEJA Jeanette A. G. Aguila Martins, 2. EE Adalberto Nascimento, 3. EE Barão Ataliba Nogueira, 4. EE Culto à Ciência, 5. EE Francisco Glicério, 6. EE Tomás Alves, 7. EE Vila Esperança, 8. EE Vitor Meirelles, 9. EE Francisco Barreto Leme, 10. EE José Maria Matosinho e 11. EE Coriolano Monteiro.

Os trabalhos foram feitos com alunos do Ensino Fundamental e Médio, e em sua maioria conseguiram apresentar uma visão holística (integradora) e crítica sobre os problemas socioambientais considerados existentes no entorno das escolas através da percepção dos alunos, professores e da população local.

Durante a realização das atividades práticas, primeiramente, através de aulas teóricas e expositivas, os professores apresentaram aos seus alunos a proposta da atividade, a de identificar os problemas socioambientais presentes no entorno da escola e como fazer isso. Em seguida foi feita a delimitação e reconhecimento da área de estudo com a ajuda dos mapas base.

Na sequência, o professor juntamente com seus alunos, elencaram possíveis riscos socioambientais 
existentes e para cada um deles criaram legendas. Após isso, foram realizados visitas a campo para comprovação da existência de tais problemáticas através de registros fotográficos e entrevistas aplicadas com moradores. Por fim, com todos os dados coletados e organizados pelos grupos, foram elaborados os mapas.

Entre os resultados obtidos, pode ser destacada a imensa variedade de situações de risco ambiental, pois a cidade de Campinas está inserida no contexto das demais metrópoles brasileiras, nas quais há uma íntima convivência entre um enorme contingente humano com as alterações ambientais negativas típicas de locais com intensas atividades econômicas.

No caso deste trabalho, essa diversidade foi observada também em função da localização variada e bem distribuída das escolas, o que possibilitou trabalhos em áreas urbanas centrais, em bairros próximos ao centro da cidade, e em áreas periféricas com graus distintos de urbanização, inclusive muito próximas de áreas rurais.

Por outro lado, houve uma importante identificação ampla e variada de elementos considerados positivos ao ambiente, como por exemplo, bosques, áreas verdes e de lazer, fragmentos de mata

Como forma de exemplificar as atividades apresentadas e descritas, seguem algumas imagens retiradas do trabalho de conclusão apresentado por duas professoras.

O primeiro deles foi organizado e orientado pela professora de Geografia Érika Wolmer, atuante na escola E.E. Tomás Alves, e realizado com alunos do 9o ano do Ensino Fundamental (figuras 1, 2), e mapa final com inserção dos símbolos gráficos elaborado pela equipe organizadora do curso. (Figura 3)

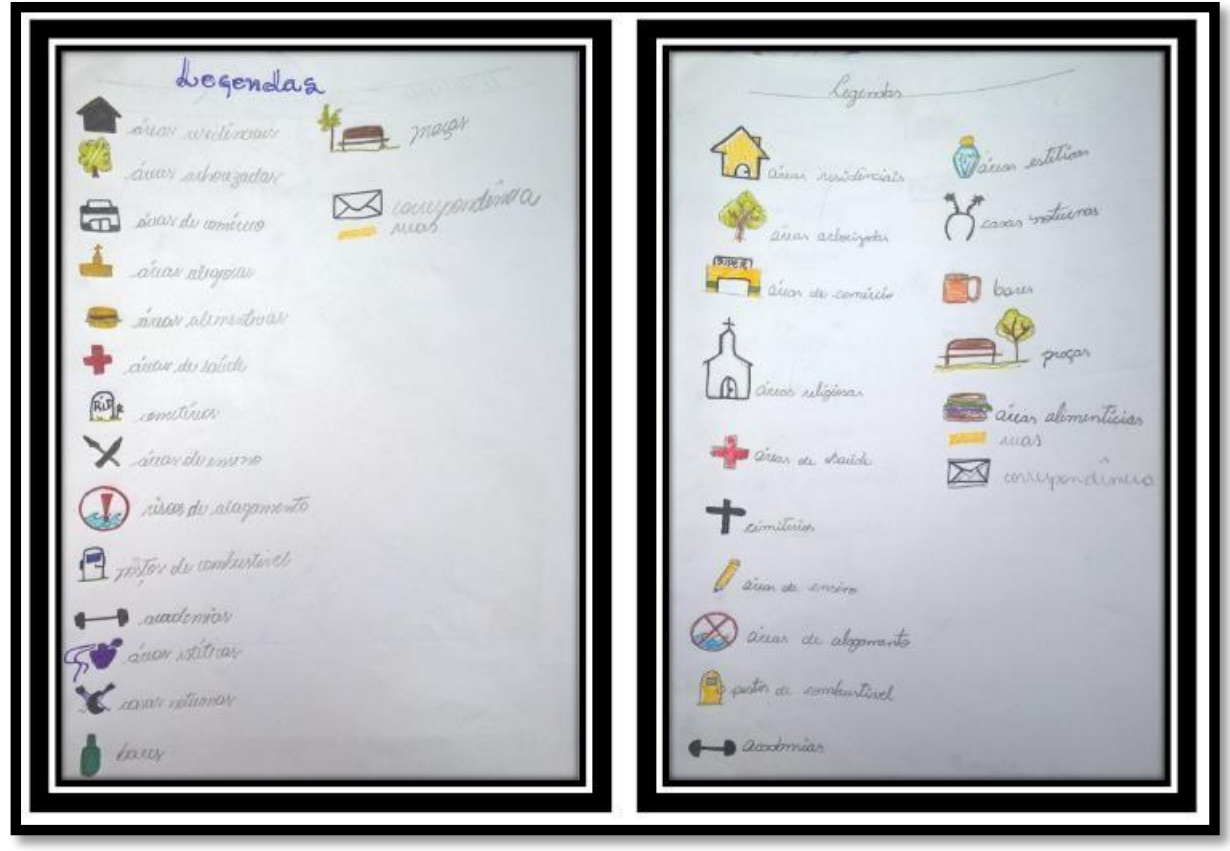

Figura 01. Exemplo de legendas criadas pelos alunos da Escola Tomás Alves para os mapeamentos 


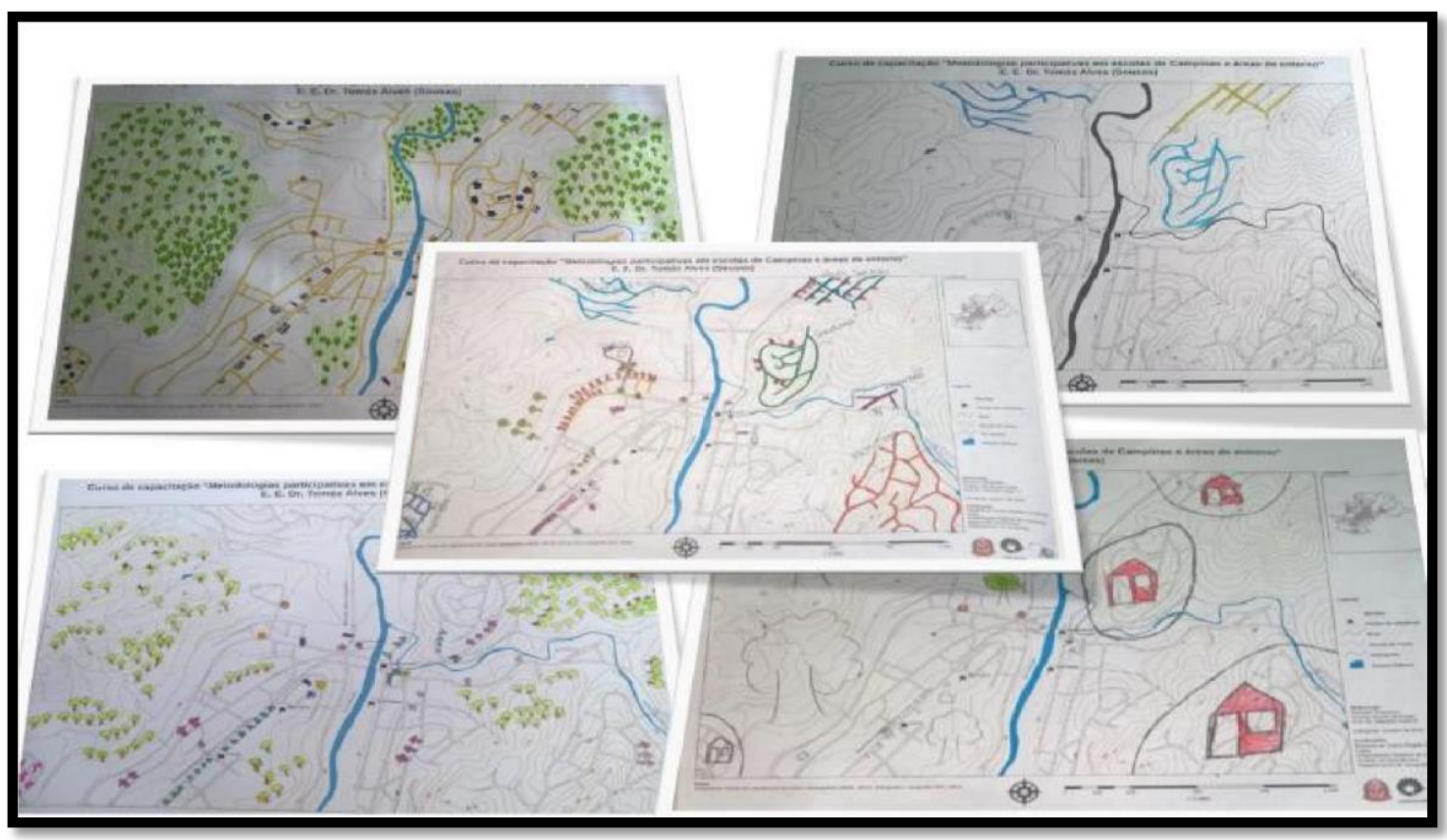

Figura 02. Mapeamento participativo socioambiental pronto e feito pelos alunos do 9o ano da E. E. Tomás Alves

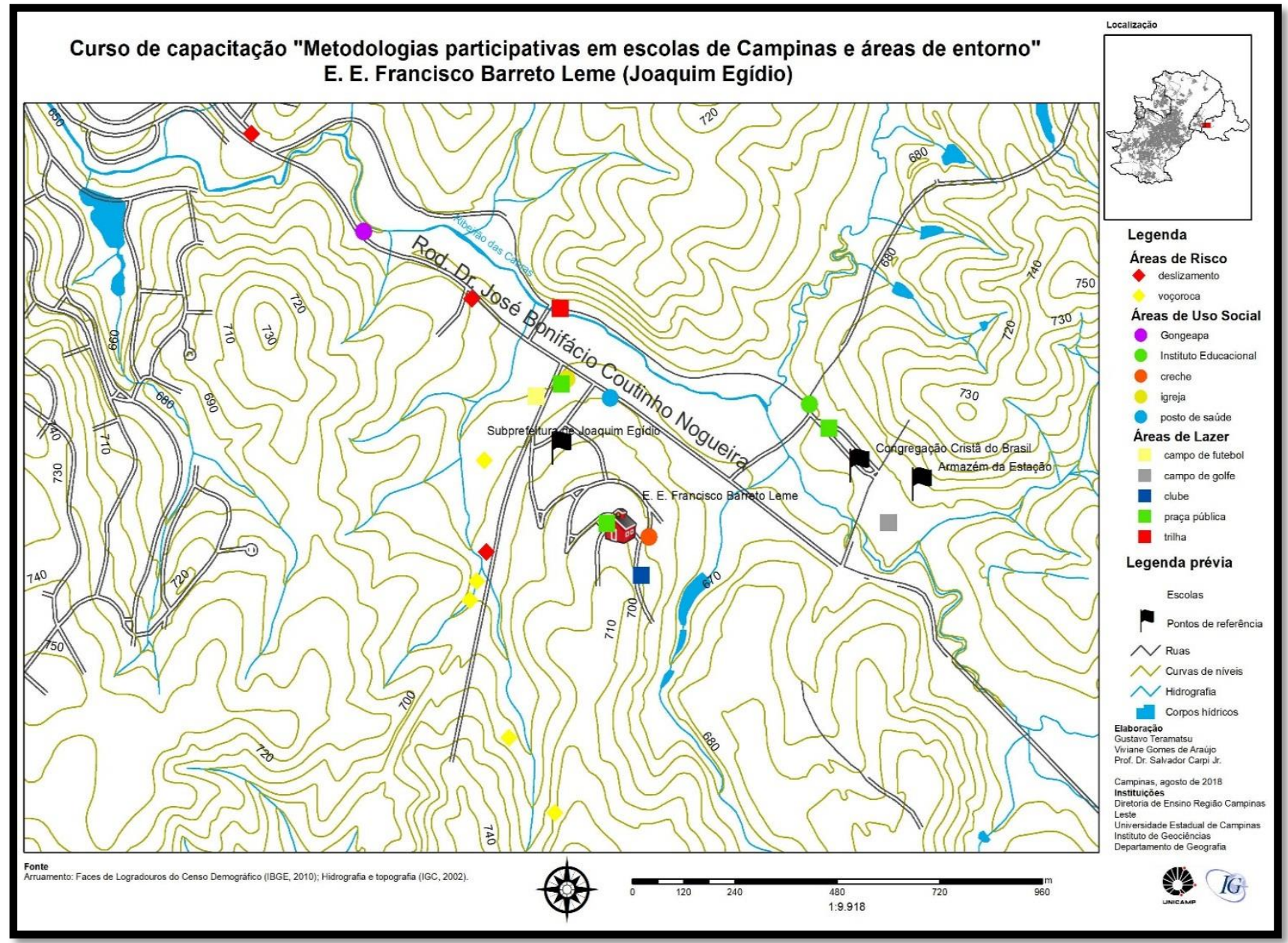

Figura 03: Mapa ambiental participativo da área de entorno da E.E. Tomás Alves

Para0nde!?, Porto Alegre, v.10, n.1, p.194-204, 2018. Edição Especial: XII ENANPEGE http://seer.ufrgs.br/paraonde 
Um segundo trabalho exemplificado foi o da professora Pitty de Mello, atuante na escola E.E. Barão de Ataliba Nogueira, e realizado com alunos do Ensino Médio (figuras 4, 5), e mapa final com inserção dos símbolos gráficos elaborado pela equipe organizadora do curso. (Figura 6)

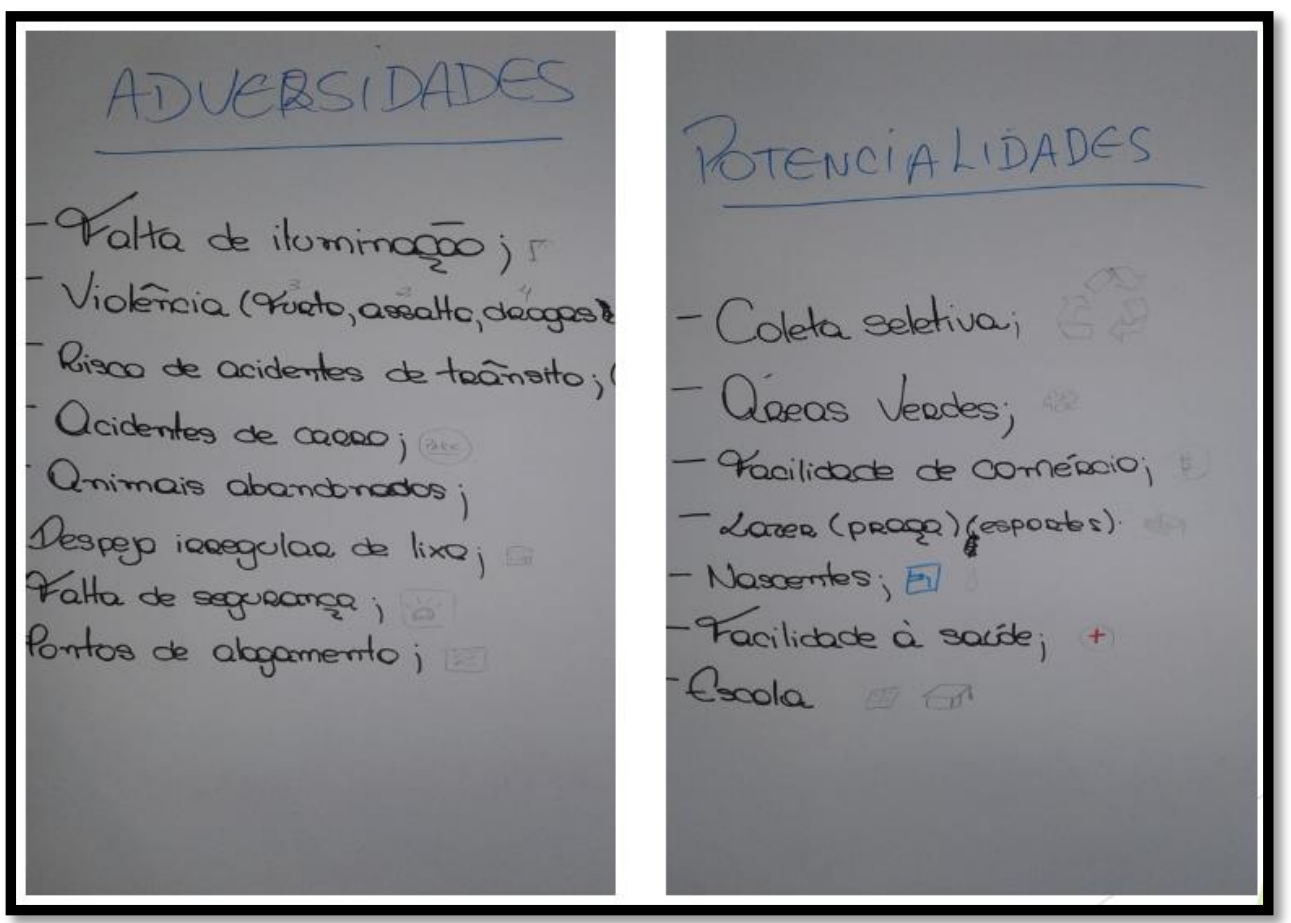

Figura 4: Exemplo de legendas criadas pelos alunos da Escola Barão Ataliba Nogueira para os mapeamentos

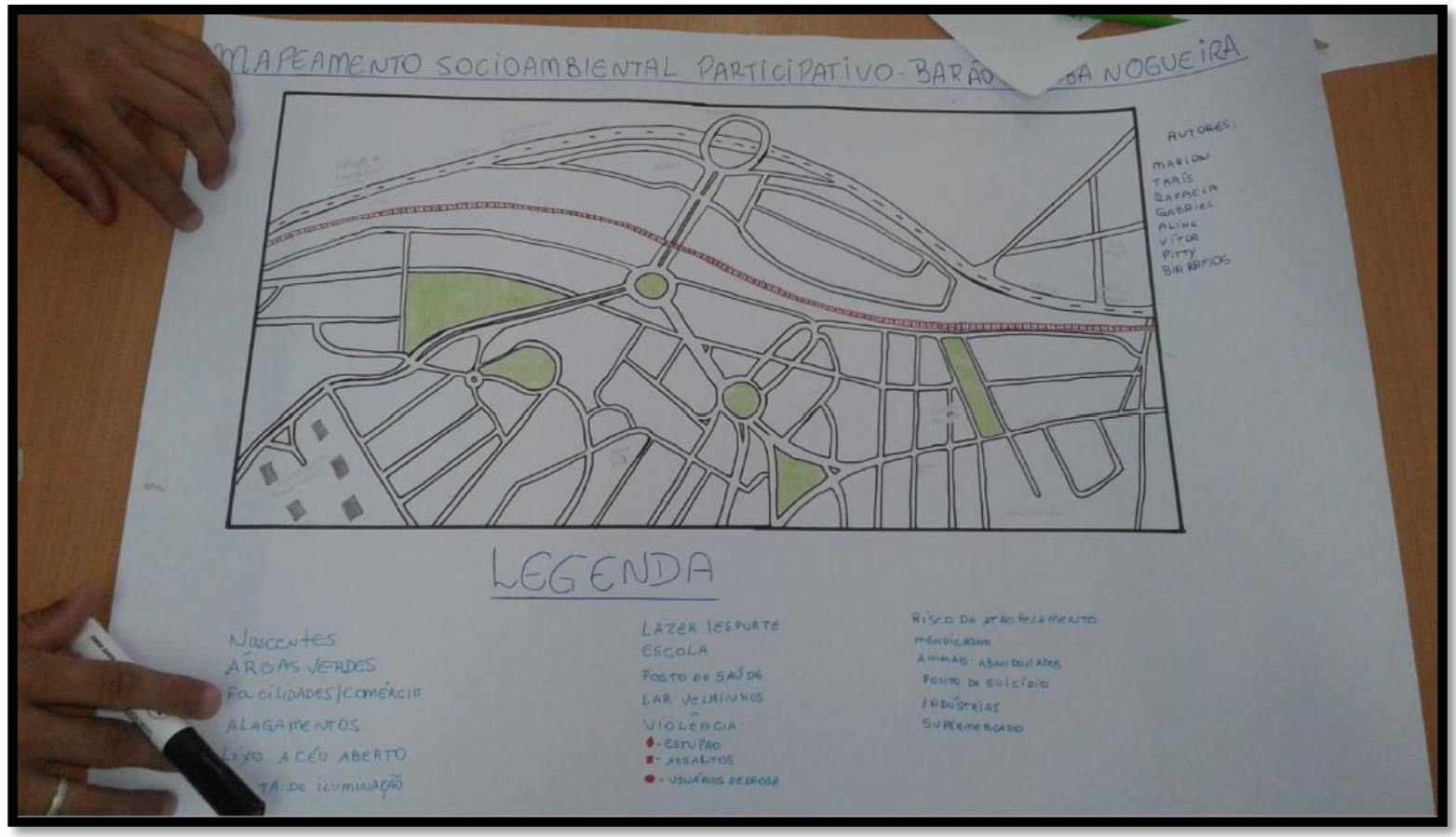

Figura 5: Uma das etapas do mapeamento ambiental participativo feito pelos alunos do Ensino Médio da escola E.E. Barão Ataliba de Nogueira 


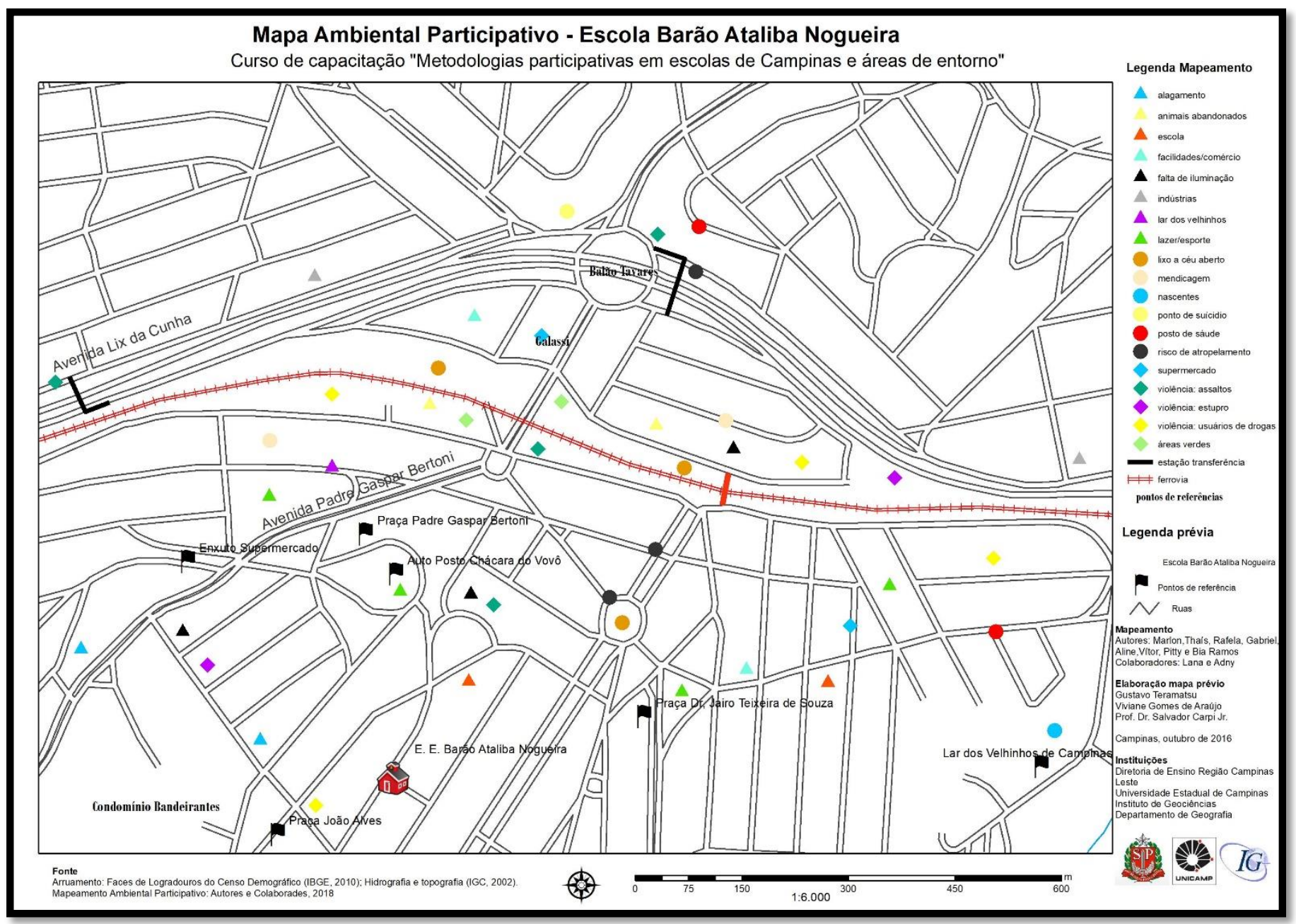

Figura 6: Mapa ambiental participativo da área de entorno da E.E. Barão Ataliba Nogueira

Em suma, a partir deste exercício, foi possibilitado aos alunos e professores das escolas envolvidas uma reflexão sobre as identidades locais destas escolas e seus valores culturais através da estimulação e valorização de soluções coletivas, ou seja, a iniciativa de se trabalhar com a resolução (ou a busca dela) dos problemas ambientais de forma participativa na comunidade escolar, envolvendo também a comunidade de moradores.

No caso da disciplina Geografia, a partir desta foi possível estabelecer ligações com a construção do conceito de paisagem através da prática da observação, assim como construir a memória do lugar, trabalhar conceitos sobre cartografia por conta da utilização de mapas, além de fazer com que os alunos passassem a conhecer melhor as adversidades e potencialidades do entorno de suas escolas.

Além de tudo, a atividade também possibilitou a discussão sobre o papel da escola/educação na comunidade, assim como a importância de propostas pedagógicas libertadoras e emancipadoras sobre gestão democrática no espaço escolar, contribuindo para que o aluno adquirisse uma visão da realidade e ganhasse subsídios para transformar em um disseminador de práticas cidadãs.

\section{Referências}

ATLAN, Henri. Entre o cristal e a fumaça: ensaio sobre a organização do ser vivo. Tradução de Vera Ribeiro. Rio de Janeiro: Jorge Zahar Ed., 1992. 
AMADOR, Maria Betânia Moreira. Interconexão Biogeografia, Biodiversidade, Lugar. In: AMADOR, Maria Betânia Moreira, BENINI, Sandra Medina. A complexidade do "lugar" e do "não lugar" numa abordagem geográfico-ambiental (Orgs.). Tupã, SP: Editora ANAP, 2016.

BRASIL. PNEA - Política Nacional de Educação Ambiental. Lei no 9.795/99.

BRIGUENTI, Ederson da Costa. 0 ensino de cartografia no contexto escolar local: a construção de uma proposta. In:COMPIANI, Maurício (Org.) Ribeirão Anhumas na escola: projeto de formação continuada elaborando conhecimentos escolares relacionados à ciência, à sociedade e ao ambiente. Curitiba: EDITORA CRV, 2013, p. 171-184

BOTÊLHO, L.A.V., SANTOS, F.K.S. o Lugar como referência para a construção de uma Educação Ambiental Geográfica Crítica: uma análise reflexiva sobre o bairro. Anais do XI - Encontro Nacional da Anpege, 2015.

CAVALCANTI, Lana de Souza. Geografia, escola e construção de conhecimentos. Campinas: Papirus, 13 ed. 1998.

CARPI JUNIOR, S.; LEAL, A.; DIBIESO, E. Mapeamento de riscos ambientais e planejamento participativo de bacias hidrográficas: o caso do manancial Rio Santo Anastácio, SP-Brasil. Territorium (Coimbra), v. 19, p. 85, 2012. Disponível em: https://www.uc.pt/fluc/nicif/riscos/Documentacao/Territorium/T19 artg/T19 Artigo 10.pdf.Acesso em: 02 ago. 2018

DAGNINO, R. de S; CARPI JUNIOR. História, Desafios e Perspectivas do Mapeamento Ambiental Participativo no Estado de São Paulo, In: DIAS, L.S.: BENINI, S. Estudos Ambientais Aplicados em Bacias Hidrográficas. 2 ed. Tupã, ANAP, pp. 13-28, 2016.

FREIRE, Paulo. Educação e mudança. São Paulo: Editora Paz e Terra, 1979.

LOUREIRO, Carlos Frederico B. Educação ambiental crítica: contribuição e desafios. In: Vamos cuidar do Brasil: conceitos e práticas em educação ambiental na escola. Brasília. Ministério da Educação, Coordenação Geral de Educação Ambiental: Ministério do Meio Ambiente, Departamento de Educação Ambiental: UNESCO, 2007.

MORIN, Edgar. Os sete saberes necessários a educação do futuro. São Paulo; Cortez, 2011.

PORTO-GONÇALVES, Carlos Walter. A globalização da natureza e a natureza da globalização. Rio de Janeiro: Civilização brasileira, 2006.

SANTOS, Ricardo dos; LEAL, Antônio Cesar. Educação e Gestão Ambiental Participativa. In DIAS, Leonice Seolin; LEAL, Antonio Cezar; CARPI JUNIOR, Salvador (Orgs.). Educação Ambiental: conceitos, metodologia e práticas. Tupã: ANAP, 2016.

SILVA, Cátia Antônia da. Educação socioambiental na escola: algumas experiências do cotidiano à luz da metodologia de ensino da cartografia da ação social. 1. Ed - Rio de Janeiro: Consequência, 2011.

SOUZA, Rosemeri Melo. Vertentes ideológicas de apropriação dos sentidos de natureza no discurso ambientalista brasileiro. In: SERRES, Michel. O contrato natural. Lisboa, Edições Piaget, 1990.

TRISTÃO, Martha. A educação ambiental na formação de professores: redes de saberes. São Paulo: Annablume; Vitória: Facitec, 2004.

TUAN, Yi-Fu. Topofilia: um estudo da percepção, atitudes e valores do meio ambiente. Tradução de Lívia de Oliveira. São Paulo: DIFEL, 2012. 